\title{
Componentes Bioactivos de Diferentes Marcas de Café Comerciales de Panamá. Relación entre Ácidos Clorogénicos y Cafeína
}

\author{
Aracelly Vega*, Javier A. De León, Stephany M. Reyes y Stepfanie Y. Miranda \\ Centro de Investigación en Recursos Naturales, Universidad Autónoma de Chiriquí. Apartado Postal 0427, \\ Chiriquí, República de Panamá (e-mail: aravega@cwpanama.net). \\ ${ }^{*}$ Autor a quien debe ser dirigida la correspondencia
}

Recibido Nov. 23, 2017; Aceptado Feb. 6, 2018; Versión final Mar. 6, 2018, Publicado Ago. 2018

\begin{abstract}
Resumen
El objetivo de este estudio fue evaluar el contenido de componentes bioactivos, actividad antioxidante y relación ácidos clorogénicos/cafeína de 34 cafés comerciales de Panamá. Se identificaron y cuantificaron diez compuestos bioactivos del extracto acuoso de café por cromatografía líquida de alta resolución y se determinó la actividad antioxidante por el método del radical 2,2'-azino-bis-(3-etilbenzotiazolina-6-sulfónico). Los componentes bioactivos determinados fueron: los ácidos 3-cafeoilquínico, 4-cafeoilquínico y el 5cafeoilquínico; los isómeros ácidos 4,5-dicafeoilquínico, 3,4-dicafeoilquínico, 3,5-dicafeoilquínico; cafeína, los ácidos p-cumárico, gálico y cafeico. Los ácidos clorogénicos y la cafeína fueron los componentes bioactivos del café presentes en mayor proporción. La correlación entre ácidos clorogénicos y la actividad antioxidante fue de $\mathrm{R}^{2}=0.69$, mientras que, para el contenido de cafeína y la actividad antioxidante fue de $\mathrm{R}^{2}=0.16$. Una taza de café de $100 \mathrm{~mL}$ con $10 \mathrm{~g}$ de café de la variedad geisha aporta $92.8 \mathrm{mg}$ de cafeína y $394.2 \mathrm{mg}$ de ácidos clorogénicos.
\end{abstract}

Palabras clave: ácidos clorogénicos; cafeína; café geisha; componentes bioactivos; actividad antioxidante

\section{Bioactive Components of 34 Commercial Brands of Coffee from Panama: Relationship between Chlorogenic acids and Caffeine}

\begin{abstract}
The objective of this study was to evaluate the content of bioactive components, the antioxidant activity and the relationship between chlorogenic acids and caffeine in 34 brands of commercial coffee from Panama. Ten bioactive compounds from the aqueous coffee extract were identified and quantified by high performance liquid chromatography and the antioxidant activity was determined by the method of radical 2,2azinobis-(3-ethylbenzothiazoline-6-sulphonate). The bioactive components considered in the study were: 3 caffeoylquinic, 4-caffeoylquinic, 5-caffeoylquinic acids, the isomers 4,5-dicaffeoylquinic, 3,4-dicaffeoylquinic, 3,5-dicaffeoylquinic acids; caffeine, p-coumaric acid, gallic acid and caffeic acid. Chlorogenic acids and caffeine were the bioactive components of coffee present in greater proportion. The correlation between chlorogenic acids and antioxidant activity was $\mathrm{R}^{2}=0.69$ while the correlation between the caffeine content and the antioxidant activity was $R^{2}=0.16$. A cup of $100 \mathrm{~mL}$ coffee with $10 \mathrm{~g}$ of coffee of the geisha variety provides $92.8 \mathrm{mg}$ of caffeine and $394.2 \mathrm{mg}$ of chlorogenic acids.
\end{abstract}

Keywords: chlorogenic acids; caffeine; geisha coffee; bioactive components; antioxidant activity 


\section{INTRODUCCIÓN}

Los compuestos fenólicos son metabolitos secundarios producidos por una amplia variedad de organismo en la naturaleza; en el caso de las plantas algunos son utilizados como sistema de defensa ante patógenos y como protección contra la radiación ultravioleta. En la mayoría de las plantas superiores se encuentran compuestos fenólicos en un amplio rango, presentes en frutas, cereales, vegetales, legumbres y bebidas, como el vino, té y café (Farah y Donangelo, 2006). Los compuestos fenólicos tienen propiedades antioxidantes y esto explica sus beneficios a la salud, ya que, se ha encontrado que ellos son protectores potenciales contra enfermedades degenerativas crónicas del ser humano como cataratas, enfermedades neurodegenerativas, cáncer y enfermedades cardiovasculares (Shahidi y Chandrasekara, 2010). La dieta juega un importante rol como fuente de antioxidantes exógenos, tales como vitaminas, carotenoides, minerales como selenio y especialmente los polifenoles (Grosso et al., 2014). El café contribuye con el $64 \%$ del total de consumo de antioxidantes del ser humano (Svilaas et al., 2004). En el grano del café verde los compuestos fenólicos están presentes predominantemente como una familia de ésteres formados entre ácidos hidroxicinámicos y ácidos quínicos colectivamente conocidos como ácidos clorogénicos (CGAs) (Clifford y Clifford, 1999). El ácido clorogénico en mayor concentración en el grano de café verde es el ácido 5-cafeoilquínico (5-CQA). Otros isómeros son ácido 4-cafeoilquínico (4-CQA) y ácido 3-cafeoilquínico (3-CQA). Adicionalmente, hay otros isómeros con 2 moléculas de ácido cafeico tales como ácido 3,4-dicafeoilquínico, ácido 3,5-dicafeoilquínico y ácido 4,5-dicafeoilquínico (Babova et al., 2016). Los autores de este artículo utilizaron la nomenclatura IUPAC, (1976). La concentración de los CGAs en el café verde puede representar hasta el 14\% del peso del grano y tiene un marcada influencia en determinar la calidad y la formación del olor del café (Farah y Donangelo, 2006; Zanín et al., 2016).

Otros compuestos fenólicos están presentes en el grano de café aunque en menor proporción. Los compuestos fenólicos no flavonoides como los ácidos fenólicos y ácidos benzoicos: ácido gálico, ácido $p$ hidroxibenzoico, ácidos hidroxicinámicos como ácido cumárico y ácido cafeico (Clifford y Clifford, 1999; Kreicbergs y Dimins, 2011). El ácido $p$-cumárico (CoA), es un metabolito predominante en las plantas con propiedades antioxidantes y anti-inflamatorias. Los datos muestran que CoA es un compuesto antioxidante con buena actividad antiplaquetaria a dosis que pueden ser obtenidas de la dieta, sugiriendo posible aplicación para la prevención de enfermedades vasculares (Luceri et al., 2017). El ácido clorogénico del café verde, 5-CQA y el isómero 3,5-diCQA protegen las células del hígado humano contra el estrés oxidativo a concentraciones fisiológicas. El tostado afecta drásticamente la composición física y química de los granos del café, provocando la degradación y transformación de los polifenoles. Aunque se forman otros compuestos por el tostado, éstos no compensan la pérdida de ácidos hidroxicinámicos ni la actividad antioxidante del café verde (Perrone et al., 2012; Samo et al., 2013; Vega et al., 2017). Aunque CGAs se degradan durante el tostado, la bebida de café es abundante en estos compuestos, probablemente la fuente de CGAs de mayor concentración en la dieta. Los consumidores de café pueden tener un consumo diario de CGAs hasta de 1 gramo (Perrone et al., 2012).

Otros compuestos bioactivos encontrados en el café verde son las metilxantinas, cafeína (Caf), teobromina; siendo la cafeína el principal alcaloide en el café y su concentración depende de la variedad, proceso de tostado y preparación de la bebida (Hečimović et al., 2011). En las diferentes marcas de café comerciales de Panamá el contenido de cafeína está en un rango de 0.26 a $2.00 \%$ en peso seco (Vega et al., 2014). A pesar de los efectos controversiales de la cafeína y otros compuestos presentes en el café, la utilización de los granos de café verde está ganando un increíble interés en la industria nutraceútica y farmacológica debido a que ellos son aceptados como una fuente de compuestos que poseen actividad antioxidante como los ácidos clorogénicos. Por otro lado, el alto contenido de cafeína baja la aplicabilidad de los extractos de café verde para preparar suplementos dietéticos para ser usados como antioxidantes, debido a su conocido efecto en el sistema nervioso central. Es por eso que el mercado requiere la identificación de cafés con una alta relación ácido clorogénico/cafeína (Babova et al., 2016). En este contexto, el objetivo de este estudio fue evaluar el contenido de componentes bioactivos, su actividad antioxidante y la relación ácidos clorogénicos/cafeína que hay en una taza de café, de 34 marcas de cafés comerciales de Panamá.

\section{METODOLOGÍA}

Las muestras de café tostado y molido se obtuvieron de los supermercados de las provincias de Chiriquí, Veraguas, Coclé y Panamá. Se tomaron muestras al azar y con fecha de expiración posterior al análisis. En el laboratorio, las muestras comerciales con empaque de plástico transparente se cubrieron con papel aluminio para protegerlas de la luz y se guardaron a $0^{\circ} \mathrm{C}$ hasta que se analizaron (Vega et al., 2017). Todas las muestras son de la especie Coffea arabica; 8 son de variedad geisha, 1 variedad pacamara y 9 no se le identificó la variedad en los empaques comerciales. Según Miranda (2007), en Panamá se cultivan para fines comerciales las especies Coffea arabica (Café Arábica) con varios cultivares entre ellos: Typica, Caturra Rojo, Catuai Rojo, Borbón, Mundo Novo, MIDA 96, Pacamara y Geisha. Las muestras de café puro son cultivadas en tierras altas $(>900 \mathrm{msnm})$, excepto la \#14 y 15 que son cultivadas en tierras bajas (<900msnm). Las muestras de café mezcladas con maíz contienen café cultivado en tierras bajas. 


\section{Reactivos y solventes}

Los estándares de ácido 5-cafeoilquínico (pureza: $\geq 95.0 \%$ ), ácido 3-cafeoilquínico (pureza: $\geq 98.0 \%$ ), ácido cafeico (pureza: $\geq 98.0 \%$ ) y ácido $p$-cumárico (pureza: $\geq 98.0 \%$ ) fueron comprados de Sigma-Aldrich (St. Louis, MO). La cafeína (pureza: $\geq 98.5 \%$ ) fue obtenida de Spectrum Quality Products (New Brunswick, NJ). Los solventes metanol (pureza: 99.8\%) y ácido trifluoroacético (pureza: 99.5\%) de grado HPLC obtenidos de Tedia (United States) y el ácido cítrico grado reactivo de AppliChem (Germany).

\section{Obtención del extracto acuoso del café}

El extracto acuoso fue obtenido utilizando la metodología propuesta por Jeszka-Showron et al., (2016) con algunas modificaciones. La muestra de café comercial ( $0.5 \mathrm{~g}$ si es café mezclado y $0.25 \mathrm{~g}$ si es café puro) fue mezclada con $25 \mathrm{~mL}$ de agua destilada y se colocó en una plancha Biomega (H-4000-HS) a calentar hasta alcanzar la temperatura de $90^{\circ} \mathrm{C}$ y se mantuvo calentando durante 5 minutos a temperatura constante. Se dejó enfriar y luego se trasvasó la muestra a un tubo para centrífuga de $50 \mathrm{~mL}$ y se centrifugó por 15 minutos a 13640 G's (10000 rpm) con una temperatura de $5^{\circ} \mathrm{C}$ (Hettich Zentrifugen Rotina 38R, radio del rotor $122 \mathrm{~mm}$ ). El sobrenadante se decantó en un matraz volumétrico de $25 \mathrm{~mL}$ y se aforó con agua destilada hasta la marca. Antes de inyectar en el sistema HPLC, el sobrenadante diluido se filtró a través de unos filtros de jeringa de $0.45 \mu \mathrm{m}$ y de diámetro de $25 \mathrm{~mm}$.

\section{Identificación y cuantificación de compuestos fenólicos del café por HPLC.}

Se usó la metodología propuesta por Wen et al., (2005), con algunas modificaciones. La identificación y cuantificación de los compuestos fenólicos se llevó a cabo en un sistema Agilent 1260 Infinity, con bomba cuaternaria (G1311C), compartimiento de columna termostatizado (G1316A), detector de arreglo de diodos (G1315D) operando a 325 y 280 nm e inyección manual (Rheodyne). La separación se llevó a cabo con una columna ZORBAX SB-C18 Stable Bond Analytical $(4.6$ × $150 \mathrm{~mm}, 5 \mu \mathrm{m})$. Las condiciones de separación establecidas fueron las siguientes: volumen de inyección de $20 \mu \mathrm{L}$, flujo de $0.4 \mathrm{~mL} / \mathrm{min}$, fase móvil A (agua con $0.02 \%$ de ácido trifluoroacético), fase móvil B (metanol con $0.02 \%$ de ácido trifluoroacético), temperatura de $25^{\circ} \mathrm{C}$ y tiempo de corrida de $60 \mathrm{~min}$. El gradiente programado fue el siguiente: $98: 2$ (solvente A: solvente B) a los $0 \mathrm{~min}, 68: 32$ a los $30 \mathrm{~min}, 60: 40$ a los $40 \mathrm{~min}, 60: 40$ a los $45 \mathrm{~min}$ y 98:2 a los $50 \mathrm{~min}$.

La identificación se llevó a cabo por la comparación del tiempo de retención de la muestra con el tiempo de retención de los respectivos estándares. La determinación de la concentración de los compuestos se realizó utilizando curvas de calibración hechas para cada estándar, ácido 5-CQA y 3-CQA en un rango de 0.5 a $100 \mathrm{mg} / \mathrm{L}$, ácido cafeico, gálico y p-cumárico en un rango de 0.2 a $10 \mathrm{mg} / \mathrm{L}$ y la cafeína se cuantificó en un rango de 10 a $250 \mathrm{mg} / \mathrm{L}$. Para cuantificar el ácido 4-CQA, se utilizó directamente la curva de ácido 5-CQA, por la similitud del coeficiente de extinción molar de los isómeros del ácido 5-CQA (Nagaele, 2016).

Para la determinación de los isómeros (3,4-diCQA; 3,5-diCQA; 4,5-di-CQA), se usó la metodología propuesta por Farah et al., (2005) con algunas modificaciones. Las condiciones de separación establecidas fueron las siguientes: volumen de inyección de $20 \mu \mathrm{L}$, flujo de $0.5 \mathrm{~mL} / \mathrm{min}$, fase móvil A (ácido cítrico $10 \mathrm{mM}$ (80\%), ajustado a pH 2.5 con $\mathrm{HCl} 6 \mathrm{~N}$ y metanol (20\%) que se adicionó previamente a la solución de ácido cítrico para evitar la formación de burbujas en el sistema), fase móvil B (metanol), temperatura de $25^{\circ} \mathrm{C}$ y tiempo de corrida de $62 \mathrm{~min}$. El gradiente programado fue el siguiente: 100:0 (solvente A: solvente B) a los 0 $\min , 100: 0$ a los $19 \mathrm{~min}, 80: 20$ a los $25 \mathrm{~min}, 80: 20$ a los $35 \mathrm{~min}, 60: 40$ a los $50 \mathrm{~min}, 60: 40$ a los $60 \mathrm{~min}$ y 100:0 a los $61 \mathrm{~min}$. La concentración de los isómeros se calculó utilizando la siguiente fórmula:

$\mathrm{C}=\frac{\mathrm{RF} \varepsilon 1 \mathrm{MR} 2 \mathrm{~A}}{\varepsilon 2 \mathrm{MR} 1}$

Donde $C$ es la concentración del isómero en cuestión (mg/L); RF es el factor de respuesta del estándar de 5-CQA (expresado en $\mathrm{mg} / \mathrm{L}$ ); $\varepsilon_{1}$ coeficiente de extinción molar del 5-CQA; $\varepsilon_{2}$ coeficiente de extinción molar del isómero en cuestión; $\mathrm{MR}_{1}$ es el peso molecular del 5-CQA (354.1 g/mol); MR2 es el peso molecular relativo del isómero en cuestión $(516.2 \mathrm{~g} / \mathrm{mol}$ ) (Nollet y Toldrá, 2012) y A es el área del pico del isómero en cuestión. Los coeficientes de extinción molar (x 104) utilizados fueron los siguientes: A 330nm, 5-CQA=1.95; $4-C Q A=1.80 ; 3-C Q A=1.84 ; 3,4-d i C Q A=3.18 ; 3,5-\operatorname{diCQA}=3.16 ;$ y 4,5-diCQA=1.84.

\section{Determinación de la actividad antioxidante por el método del radical ABTS.+}

Se usó la metodología propuesta por Pérez-Hernández, et al., (2012) con algunas modificaciones. Este método mide la capacidad relativa de los antioxidantes para neutralizar el radical ABTS ${ }^{+}$generado en fase acuosa y se compara con un estándar de Trolox (análogo soluble en agua de la vitamina E). Para generar el 
catión ABTS.+ se pesaron 19.2 mg de ácido 2,2'-azino-bis (3-etilbenzotiazolin-6-sulfonico) y se disolvió en 5 $\mathrm{mL}$ de agua destilada para obtener una concentración de $7 \mathrm{mM}$. Luego se le adicionó $88 \mu \mathrm{L}$ de persulfato de potasio $140 \mathrm{mM}$. La solución resultante se homogenizó y se dejó incubar a temperatura ambiente $\left(25^{\circ} \mathrm{C} \pm 1\right)$ en oscuridad por 16 horas. Una vez generado el radical, ABTS.+, se procedió a ajustar con etanol hasta obtener una absorbancia de $0.7 \pm 0.1$ a $754 \mathrm{~nm}$. La línea base se corrigió con etanol. Para el análisis de la muestra a $3.9 \mathrm{~mL}$ de solución de ABTS.+, previamente ajustada a una absorbancia de $0.7 \pm 0.1$, se le adicionó $100 \mu \mathrm{L}$ del extracto acuoso de café y se agitó vigorosamente. La muestra se leyó inmediatamente (Abs $t=0 \mathrm{~min}$ ) y luego a los $7 \mathrm{~min}$ (Abs $\mathrm{t}=7 \mathrm{~min}$ ), en un espectrofotómetro UV/VIS (PG Instruments Ltd, modelo T70+ UV/VIS Spectrometer) a $754 \mathrm{~nm}$. La curva de calibración se construyó con Trolox en un rango de 0 a $1.0 \mathrm{mM}$. La actividad antioxidante se calculó con la curva de calibración y se expresó en mmol trolox/g de muestra (Pantoja, 2017).

\section{Análisis estadístico}

Los datos de los diferentes parámetros representan las medias y desviaciones estándar de cada una de las muestras por triplicado. Los datos se sometieron a pruebas ANOVA, pruebas de correlación y pruebas de rango como t de student, para establecer si existían diferencias significativas entre las muestras para cada parámetro. Todos los datos fueron tratados con el software PAST de acceso gratuito en Internet.

\section{RESULTADOS Y DISCUSIÓN}

En este estudio se analizaron 34 marcas de cafés comerciales de Panamá, los cuales son de la especie Coffea arábica (variedades geisha, pacamara y muestras sin identificar la variedad). Se cultivan en bajura<900 msnm y altura>900 msnm y se comercializan con diferentes grados de tostado y molido (Vega et al., 2017). De los 34 cafés estudiados, el $52.94 \%$ son cafés puros y $47.06 \%$ son mezclas de café con maíz, de acuerdo a lo descrito en el paquete del producto. Todos los cafés puros son de la especie Coffea arábica, de los cuales el $50.00 \%$ son muestras sin identificar la variedad (A); el 44.44\%, Coffea arábica var. geisha $(\mathrm{G})$ y el $5.56 \%$, Coffea arábica var. pacamara $(\mathrm{P})$. De los cafés puros, el $88.89 \%$ son cultivados en altura (>900 msnm) y el $11.11 \%$, en bajura (<900 $\mathrm{msnm})$.

En la tabla 1, se muestran los resultados del contenido de sustancias bioactivas como ácidos clorogénicos (CQA, di-CQA); ácidos cinámicos libres (ácido cafeico, p-cumárico) y ácido gálico, de 18 marcas de café puros comerciales de Panamá. En la tabla, los valores no conectados por la misma letra, en la misma columna, indican que son significativamente diferentes $\mathrm{t}=2.02, \alpha=0.05$. Las letras son independientes para cada uno de los parámetros evaluados. Ác. 5-CQA= ácido 5-cafeoilquínico; Ác. 3-CQA= ácido 3cafeoilquínico; Ác. 4-CQA= ácido 4-cafeoilquínico; 3,4-diCQA= ácido 3,4-dicafeoilquínico; 3,5-diCQA= ácido 3,5-dicafeoilquínico; 4,5-diCQA= ácido 4,5-dicafeoilquínico; $A G=$ ácido gálico; $C A=$ ácido cafeico; Co $A$ = ácido $p$-cumárico; $N D=$ no detectado. El contenido de ácido 5-cafeoilquínico (5-CQA), está en el rango de 86.31 a 2042.32 mg/100g; el ácido 4-cafeoilquínico (4-CQA), de 79.26 a 1052.77 mg/100g; el ácido 3cafeoilquínico (3-CQA) de 53.43 a $891.84 \mathrm{mg} / 100 \mathrm{~g}$; el éster 4,5-diCQA ND a $999.90 \mathrm{mg} / 100 \mathrm{~g}$; el éster 3,4diCQA 1.67 a $848.27 \mathrm{mg} / 100 \mathrm{~g}$; el éster 3,5-diCQA 1.05 a $650.23 \mathrm{mg} / 100 \mathrm{~g}$; ácido p-cumárico ND a $5.0 \mathrm{mg} / 100 \mathrm{~g}$; ácido gálico 0.93 a $40.33 \mathrm{mg} / 100 \mathrm{~g}$ y ácido cafeico ND a $24.55 \mathrm{mg} / 100 \mathrm{~g}$.

En los cafés los ácidos hidroxicinámicos y sus ésteres son los que están presentes en mayor proporción como se pudo comprobar en este estudio. Dentro de los ácidos hidroxicinámicos el ácido Ác. 5-CQA es el que está en mayor proporción. Si comparamos los cafés, el de mayor contenido de ácido 5-CQA es de la variedad geisha $(2042.32 \mathrm{mg} / 100 \mathrm{~g})$ y el de menor contenido de ácido 5-CQA es el café de especie arábica de bajura $(86.31 \mathrm{mg} / 100 \mathrm{~g})$. Hay estudios que indican que las condiciones de cultivo como la altura modifican las características de los cafés como su composición (Guyot et al., 1996). Los ácidos cinámicos libres como el cafeico y el $p$-cumárico se liberan durante el proceso del tostado del café y va a depender del tiempo y temperatura del tostado (Clifford y Clifford, 1999). Esto explica la variabilidad de los contenidos de estos compuestos ya que a través de encuestas a los caficultores y según el rótulo del empaque de los cafés, se usan diferentes métodos de tostados (torrefacto city; tueste suave; expreso tueste oscuro; tueste claro; tostado intermedio; tostado oscuro), en los diferentes cafés comerciales de Panamá.

En la tabla 1 se muestran los resultados de la prueba t de student, la cual resultó significativa, con un valor de $\mathrm{t}=2.02, \quad \alpha=0.05$ para las diferentes marcas de café en los 9 parámetros evaluados. Como se puede observar hay variabilidad en todos los parámetros. Durante el proceso del tostado los ácidos clorogénicos se descomponen y forman nuevos compuestos. En este estudio se utilizaron cafés de la especie arábica y de diferentes variedades: pacamara (1), geisha (8) y sin identificar la variedad (9). Los cafés con mayor contenido de ácidos clorogénicos son de la especie arábica de altura como el geisha y el pacamara y los de más bajo contenido son los de bajura. 
Tabla 1: Contenido de sustancias bioactivas extraídos en agua de las muestras (\#) de cafés puros comerciales de Panamá.

\begin{tabular}{|c|c|c|c|c|c|c|c|c|c|}
\hline \# & $\begin{array}{l}\text { Ác. 5-CQA } \\
(\mathrm{mg} / 100 \mathrm{~g})\end{array}$ & $\begin{array}{l}\text { Ác. 3-CQA } \\
(\mathrm{mg} / 100 \mathrm{~g})\end{array}$ & $\begin{array}{l}\text { Ác. 4-CQA } \\
(m g / 100 g)\end{array}$ & $\begin{array}{l}3,4-d i C Q A \\
(m g / 100 g)\end{array}$ & $\begin{array}{l}\text { 3,5-diCQA } \\
(\mathrm{mg} / 100 \mathrm{~g})\end{array}$ & $\begin{array}{l}\text { 4,5-diCQA } \\
(\mathrm{mg} / 100 \mathrm{~g})\end{array}$ & $\begin{array}{l}A G \\
(m g / 100 g)\end{array}$ & $\begin{array}{l}C A \\
(m g / 100 g)\end{array}$ & $\begin{array}{l}\text { CoA } \\
(m g / 100 g)\end{array}$ \\
\hline 5 & $749.89 \pm 21.74^{i}$ & $377.93 \pm 6.409$ & $454.61 \pm 7.16^{9}$ & $26.60 \pm 1.30^{f}$ & $14.74 \pm 0.78^{9}$ & $32.18 \pm 1.50^{f}$ & $13.66 \pm 0.32^{\mathrm{e}}$ & $7.99 \pm 0.48^{\mathrm{cd}}$ & N.D. \\
\hline 7 & $768.16 \pm 17.71^{i}$ & $355.18 \pm 8.53^{9}$ & $442.69 \pm 13.32^{g}$ & $18.98 \pm 1.22^{g h}$ & $11.70 \pm 0.74^{\mathrm{gh}}$ & $20.02 \pm 1.46^{9}$ & $13.35 \pm 1.10^{\mathrm{e}}$ & $4.47 \pm 0.46^{e}$ & $5.06 \pm 0.18^{a}$ \\
\hline 8 & $313.69 \pm 9.23^{1}$ & $185.41 \pm 4.76^{i}$ & $221.76 \pm 8.67^{j}$ & $6.88 \pm 0.33^{\mathrm{ik}}$ & $3.91 \pm 0.10^{j}$ & $6.06 \pm 0.49^{i j}$ & $10.32 \pm 0.32^{\mathrm{g}}$ & $4.39 \pm 0.41^{\mathrm{e}}$ & N.D. \\
\hline 11 & $694.17 \pm 25.74$ & $352.07 \pm 10.10^{g}$ & $402.52 \pm 14.56^{h}$ & $17.04 \pm 1.56^{h}$ & $10.48 \pm 0.41^{\mathrm{ghi}}$ & $17.96 \pm 0.71^{\mathrm{gh}}$ & $11.89 \pm 0.32^{f}$ & N.D. & $2.43 \pm 0.19^{d}$ \\
\hline 14 & $100.38 \pm 1.62^{n}$ & $69.28 \pm 2.07^{\mathrm{k}}$ & $93.63 \pm 2.22^{k l}$ & $1.96 \pm 0.52^{\mathrm{kl}}$ & $1.22 \pm 0.32^{j}$ & $1.02 \pm 0.09^{i j}$ & $5.84 \pm 0.23^{i}$ & N.D. & N.D. \\
\hline 15 & $86.31 \pm 2.55^{n}$ & $53.43 \pm 2.31^{\mathrm{k}}$ & $79.26 \pm 2.26^{1}$ & $1.67 \pm 0.17^{\mid}$ & $1.06 \pm 0.14^{j}$ & ND & $4.61 \pm 0.20^{j}$ & N.D. & N.D. \\
\hline 30 & $1320.60 \pm 4.24^{f}$ & $533.02 \pm 51.09 e$ & $638.97 \pm 62.20^{e}$ & $22.48 \pm 1.74^{\mathrm{fg}}$ & $13.88 \pm 1.299$ & $24.44 \pm 2.04^{\mathrm{fg}}$ & $8.52 \pm 0.15^{h}$ & $3.75 \pm 0.23^{e}$ & $2.08 \pm 0.10^{\mathrm{e}}$ \\
\hline 33 & $1674.41 \pm 43.35^{\mathrm{e}}$ & $777.58 \pm 31.30^{c}$ & $934.74 \pm 30.01^{c}$ & $57.00 \pm 3.53^{\mathrm{cd}}$ & $38.45 \pm 3.19^{\mathrm{e}}$ & $67.15 \pm 6.38^{d}$ & $16.48 \pm 0.30^{d}$ & $4.93 \pm 0.14^{e}$ & $3.37 \pm 0.27^{c}$ \\
\hline 34 & $617.92 \pm 4.95^{\mathrm{k}}$ & $297.78 \pm 4.11^{\mathrm{h}}$ & $361.91 \pm 7.67$ & $11.70 \pm 0.35^{i}$ & $6.16 \pm 0.21^{\text {hij }}$ & $10.17 \pm 0.55^{\mathrm{hi}}$ & $0.94 \pm 0.13^{k}$ & $9.02 \pm 0.83^{b c}$ & $2.28 \pm 0.16^{d}$ \\
\hline 35 & $157.44 \pm 4.68^{m}$ & $100.07 \pm 1.81^{j}$ & $124.81 \pm 1.38^{\mathrm{k}}$ & $2.85 \pm 0.15^{\mathrm{jk}}$ & $2.06 \pm 0.07^{j}$ & $4.84 \pm 0.13^{i j}$ & $3.76 \pm 0.15^{j}$ & N.D. & N.D. \\
\hline 36 & $843.67 \pm 7.69^{h}$ & $378.03 \pm 1.00^{9}$ & $477.58 \pm 12.21^{g}$ & $18.11 \pm 0.66^{g h}$ & $10.94 \pm 0.52^{g h}$ & $19.24 \pm 0.47^{g h}$ & $10.14 \pm 0.36^{g}$ & $9.15 \pm 0.13^{b c}$ & N.D. \\
\hline 37 & $936.78 \pm 66.679$ & $499.10 \pm 3.81^{\dagger}$ & $552.56 \pm 65.13^{f}$ & $20.41 \pm 0.88^{g h}$ & $10.84 \pm 1.44^{g h}$ & $20.18 \pm 0.44^{g}$ & $12.13 \pm 0.34^{f}$ & $7.26 \pm 0.24^{d}$ & $3.85 \pm 0.28^{b}$ \\
\hline 38 & $1995.64 \pm 14.59^{b c}$ & $891.85 \pm 2.86^{a}$ & $1052.77 \pm 4.55^{a}$ & $47.94 \pm 2.90^{\mathrm{e}}$ & $31.26 \pm 2.13^{f}$ & $55.25 \pm 2.76^{\mathrm{e}}$ & $9.82 \pm 0.59 \mathrm{~g}$ & $9.66 \pm 0.12^{b}$ & N.D. \\
\hline 39 & $1890.91 \pm 25.13^{d}$ & $863.80 \pm 16.32^{b}$ & $1005.61 \pm 17.95^{b}$ & $163.98 \pm 10.41^{a}$ & $117.32 \pm 8.04^{a}$ & $190.54 \pm 13.02^{a}$ & $13.16 \pm 1.05^{\mathrm{e}}$ & $8.91 \pm 0.84^{a}$ & N.D. \\
\hline 40 & $2017.94 \pm 27.33^{\mathrm{ab}}$ & $771.36 \pm 0.76^{c}$ & $919.28 \pm 7.78^{c}$ & $57.77 \pm 4.20^{\text {cd }}$ & $87.16 \pm 8.10^{c}$ & $142.59 \pm 10.57^{b}$ & $30.56 \pm 0.80^{\mathrm{b}}$ & N.D. & N.D. \\
\hline 41 & $2042.32 \pm 13.08^{a}$ & $785.05 \pm 12.99^{c}$ & $937.16 \pm 13.92^{c}$ & $58.50 \pm 4.60^{c}$ & $93.93 \pm 7.10^{\mathrm{b}}$ & $147.36 \pm 11.56^{b}$ & $27.76 \pm 0.58^{c}$ & N.D. & N.D. \\
\hline 42 & $1959.14 \pm 11.94^{c}$ & $721.62 \pm 2.34^{d}$ & $871.79 \pm 2.69^{d}$ & $53.12 \pm 3.30^{d}$ & $79.52 \pm 6.50^{d}$ & $133.20 \pm 10.90^{c}$ & $27.24 \pm 0.36^{c}$ & N.D. & N.D. \\
\hline 43 & $2029.85 \pm 20.88^{a b}$ & $838.27 \pm 13.75^{b}$ & $986.77 \pm 14.77^{b}$ & $79.90 \pm 3.80^{\mathrm{b}}$ & $122.00 \pm 6.40^{a}$ & $188.38 \pm 8.80^{\mathrm{a}}$ & $40.33 \pm 0.60^{\mathrm{a}}$ & N.D. & N.D. \\
\hline
\end{tabular}


En estudios anteriores se encontró que las muestras de Coffea arábica (variedades geisha y pacamara) y algunas muestras de Coffea arábica (muestras sin identificar la variedad) de altura son los que tienen mayor contenido de polifenoles totales (incluyendo los clorogénicos). Y las muestras de Coffea arábica (muestras sin identificar la variedad) de bajura tienen el menor contenido de polifenoles (Vega et al., 2017). Los cafés geisha y pacamara se comercializan como cafés especiales, por lo que todo el proceso postcosecha se hace cuidando sus propiedades, sobre todo el tostado siendo éste un tueste claro a intermedio, lo que evita la descomposición de sustancias bioactivas como los ácidos clorogénicos (Samo et al., 2013).

En la tabla 2, se muestran los resultados de la concentración de los CQAs y el ácido gálico de 16 marcas de cafés mezclados, comerciales de Panamá. En la tabla, los valores no conectados por la misma letra son significativamente diferentes $\mathrm{t}=2.02 \alpha=0.05$. Las letras son independientes para cada parámetro evaluado. El contenido de 5-CQA está en el rango de 5.72 a $272.52 \mathrm{mg} / 100 \mathrm{~g}$; 3-CQA 3.62 a $125.15 \mathrm{mg} / 100 \mathrm{~g}$; 4-CQA 6.56 a $166.17 \mathrm{mg} / 100 \mathrm{~g}$ y AG 1.62 a $14.06 \mathrm{mg} / 100 \mathrm{~g}$. Los ácido cafeico, $p$-cumárico y los ésteres 3,4-diCQA, 3,5-diCQA y 4,5-diCQA no fueron detectados en los cafés mezclados con maíz. En estudios de cafés comerciales de Panamá, Vega et al., (2017), encontraron que los cafés mezclados con maíz tienen un bajo contenido de polifenoles porque el maíz aporta una baja cantidad de polifenoles.

Tabla 2: Contenido de sustancias bioactivas (extraídos en agua de las muestras (\#) de cafés mezclados comerciales de Panamá.

\begin{tabular}{|c|c|c|c|c|c|c|}
\hline \# & Composición & $\begin{array}{l}\text { Condiciones de } \\
\text { cultivo del café }\end{array}$ & $\begin{array}{l}\text { Ác. 5-CQA } \\
\text { (mg/100g) }\end{array}$ & $\begin{array}{l}\text { Ác. 3-CQA } \\
(m g / 100 g)\end{array}$ & $\begin{array}{l}\text { Ác. 4-CQA } \\
(m g / 100 g)\end{array}$ & $\begin{array}{l}A G \\
(m g / 100 g)\end{array}$ \\
\hline 1 & Café y Maíz & Bajura & $30.62 \pm 1.20^{\mathrm{fgh}}$ & $17.73 \pm 0.47^{g}$ & $28.52 \pm 0.74^{g}$ & $6.25 \pm 0.04^{\mathrm{e}}$ \\
\hline 2 & Café y Maíz & Bajura & $179.30 \pm 3.84^{b}$ & $77.53 \pm 1.24^{b}$ & $100.29 \pm 4.02^{b}$ & $14.06 \pm 0.56^{a}$ \\
\hline 3 & Café y Maíz & Bajura & $34.23 \pm 2.11^{\mathrm{fg}}$ & $19.05 \pm 1.21^{g}$ & $29.28 \pm 2.05^{9}$ & $10.02 \pm 0.36^{\mathrm{cd}}$ \\
\hline 4 & Café y Maíz & Bajura & $84.45 \pm 4.40^{\mathrm{e}}$ & $44.22 \pm 1.82^{\mathrm{e}}$ & $57.13 \pm 3.78^{e}$ & $9.37 \pm 0.21^{d}$ \\
\hline 6 & Café y Maíz & Bajura & $5.72 \pm 0.30^{i}$ & $3.62 \pm 0.16^{i}$ & $6.56 \pm 0.21^{j}$ & $10.08 \pm 1.19^{\mathrm{cd}}$ \\
\hline 10 & Café y Maíz & Bajura & $128.96 \pm 3.82^{c}$ & $69.09 \pm 1.25^{c}$ & $91.28 \pm 1.98^{c}$ & $12.40 \pm 0.37^{a b}$ \\
\hline 13 & Café y Maíz & Bajura & $82.87 \pm 2.64^{\mathrm{e}}$ & $44.63 \pm 0.92^{\mathrm{e}}$ & $61.88 \pm 1.53^{\mathrm{e}}$ & $13.69 \pm 0.38^{a}$ \\
\hline 17 & Café y Maíz & Bajura & $30.75 \pm 1.35^{\text {fgh }}$ & $9.18 \pm 0.64^{h}$ & $11.05 \pm 0.99^{i j}$ & $2.93 \pm 0.13^{\mathrm{fgh}}$ \\
\hline 20 & Café y Maíz & Bajura & $119.11 \pm 5.12^{\mathrm{c}}$ & $48.14 \pm 1.58^{e}$ & $71.18 \pm 5.02^{d}$ & $13.36 \pm 1.40^{\mathrm{a}}$ \\
\hline 21 & Café y Maíz & Bajura & $25.18 \pm 1.09 \mathrm{gh}$ & $14.04 \pm 0.69 \mathrm{gh}$ & $16.70 \pm 1.05^{\mathrm{hi}}$ & $11.26 \pm 0.23^{b c}$ \\
\hline 22 & Café y Maíz & Bajura & $130.10 \pm 6.90^{c}$ & $80.87 \pm 4.61^{b}$ & $95.60 \pm 3.74^{\mathrm{bc}}$ & $1.62 \pm 0.08^{h}$ \\
\hline 25 & Café y Maíz & Bajura & $105.96 \pm 2.20^{d}$ & $56.47 \pm 1.14^{d}$ & $64.26 \pm 1.29^{\mathrm{de}}$ & $3.80 \pm 0.29^{f g}$ \\
\hline 26 & Café y Maíz & Bajura & $272.57 \pm 7.65^{a}$ & $125.15 \pm 3.39^{a}$ & $166.17 \pm 4.55^{a}$ & $4.35 \pm 0.29^{f}$ \\
\hline 27 & Café y Maíz & Bajura & $38.88 \pm 0.82^{f}$ & $18.42 \pm 0.63^{g}$ & $22.30 \pm 0.28^{g h}$ & $2.16 \pm 0.05^{g h}$ \\
\hline 28 & Café y Maíz & Bajura & $20.58 \pm 1.35^{h}$ & $11.83 \pm 0.70^{\mathrm{h}}$ & $17.00 \pm 1.02^{\mathrm{hi}}$ & $7.69 \pm 0.72^{\mathrm{e}}$ \\
\hline 29 & Café y Maíz & Bajura & $74.40 \pm 3.58^{e}$ & $35.10 \pm 1.64^{f}$ & $42.13 \pm 1.93^{f}$ & $6.64 \pm 0.05^{\mathrm{e}}$ \\
\hline
\end{tabular}

En la tabla 2, se muestran los resultados de la prueba t de student para los 4 parámetros evaluados en las diferentes muestras de café mezclados. Se encuentra variabilidad en las diferentes muestras; de 16 marcas, para los 4 parámetros, 12 tienen concentraciones significativamente diferentes. Las 16 marcas de café de este estudio son para consumo nacional y es una mezcla de café $C$. arabica y $C$. robusta de bajura y maíz en diferentes proporciones. El proceso de tostado es diferente según la marca y por ello la variabilidad en el contenido de sustancias bioactivas.

En la tabla 3, se muestra la concentración de Ácidos clorogénicos (CGAs), cafeína (Caf) y la relación ácidos clorogénicos/cafeína (CGAs/Caf) de los 18 cafés puros comerciales estudiados. Se observa variabilidad en el contenido de CGAs que está en el rango de 219 a $4245.17 \mathrm{mg} / 100 \mathrm{~g}$ y la cafeína en el rango de 927.89 a $2008.95 \mathrm{mg} / 100 \mathrm{~g}$. El contenido de cafeína en el café depende del método de extracción con agua caliente, pero no es afectado por el grado de tostado; sin embargo los CGAs si son afectados por las temperaturas y el tiempo de tostado ya que se descomponen en otros compuestos con menos poder antioxidante. La relación CGAs/Caf está en el rango de 0.11 a 3.85. Está variabilidad se debe a que son variedades de café, 
condiciones de cultivo y grados de tostado, diferentes. Esta relación CGAs/Caf es un parámetro que indica si un café puede ser utilizado en la industria de las bebidas nutraceúticas. Si tiene un alto contenido de CGAs, se considera una bebida antioxidante. Por otro lado, el alto contenido de cafeína disminuye la aplicabilidad del café para preparar suplementos dietéticos y ser usados como antioxidantes, debido a su efecto negativo en el sistema nervioso central. Es por eso que el mercado requiere la identificación de cafés con una alta relación CGAs/Caf. En Babova et al., (2016) se concluyó que cafés C arabica de Kenia con una relación ácido clorogénico/cafeína de 1.5 era una fuente óptima de antioxidantes con aplicaciones en la industria farmacéutica y nutraceútica. En este estudio se encontró que los cafés de la variedad geisha tienen una relación CGAs/Caf en el rango de 2.48 a 3.85, por lo que se puede proponer como fuente de antioxidante en la industria nutraceútica.

Tabla 3: Contenido de ácidos clorogénicos totales, cafeína, $A B T S^{+}$, relación CGAs/Caf de los cafés puros comerciales de Panamá.

\begin{tabular}{lllllll}
\hline$\#$ & \multicolumn{1}{c}{ Especie } & $\begin{array}{c}\text { Condiciones de } \\
\text { cultivo }\end{array}$ & CGAs (mg/100g) & Caf (mg/100g) & $\begin{array}{c}\text { ABTS }{ }^{+} \\
\text {(mmol eq. } \\
\text { Trolox/g) }\end{array}$ & $\begin{array}{c}\text { Relación } \\
\text { CGAs /Caf }\end{array}$ \\
\hline 5 & C. arabica & Altura & 1582.43 & $1569.56^{\mathrm{b}}$ & $0.1781^{\mathrm{bc}}$ & 1.01 \\
7 & C. arabica & Altura & 1566.03 & $1268.83^{\mathrm{fg}}$ & $0.1628^{\mathrm{cd}}$ & 1.23 \\
8 & C. arabica & Altura & 737.72 & $1233.90^{\mathrm{gh}}$ & $0.1092^{\mathrm{jk}}$ & 0.60 \\
11 & C. arabica & Altura & 1448.75 & $1210.46^{\mathrm{h}}$ & $0.1333^{\mathrm{fgh}}$ & 1.20 \\
14 & C. arabica & Bajura & 263.30 & $1531.55^{\mathrm{b}}$ & $0.1018^{\mathrm{j}}$ & 0.17 \\
15 & C. arabica & Bajura & 219.00 & $2008.95^{\mathrm{a}}$ & $0.1236^{\mathrm{ghi}}$ & 0.11 \\
30 & C. arabica var. geisha & Altura & 2492.59 & $1006.85^{\mathrm{k}}$ & $0.1395^{\mathrm{f}}$ & 2.48 \\
33 & C. arabica var. geisha & Altura & 3386.74 & $1288.27^{\mathrm{ef}}$ & $0.1450^{\mathrm{ef}}$ & 2.63 \\
34 & C. arabica var. geisha & Altura & 1277.61 & $1349.31^{\mathrm{cd}}$ & $0.1220^{\mathrm{ghi}}$ & 0.95 \\
35 & C. arabica & Altura & 392.08 & $1288.05^{\mathrm{ef}}$ & $0.0832^{\mathrm{k}}$ & 0.30 \\
36 & C. arabica & Altura & 1699.28 & $1371.41^{\mathrm{c}}$ & $0.1354^{\mathrm{fg}}$ & 1.24 \\
37 & C. arabica & Altura & 2039.86 & $1319.62^{\mathrm{de}}$ & $0.1212^{\mathrm{hij}}$ & 1.55 \\
38 & C. arabica var. geisha & Altura & 3940.25 & $1275.15^{\mathrm{fg}}$ & $0.1764^{\mathrm{b}}$ & 3.09 \\
39 & C. arabica var. pacamara & Altura & 3760.32 & $1288.84^{\mathrm{ef}}$ & $0.1573^{\mathrm{de}}$ & 3.28 \\
40 & C. arabica var. geisha & Altura & 3996.10 & $938.19^{\mathrm{jj}}$ & $0.1362^{\mathrm{a}}$ & 3.57 \\
41 & C. arabica var. geisha & Altura & 3916.96 & $936.72^{\mathrm{j}}$ & $0.1308^{\mathrm{a}}$ & 3.62 \\
42 & C. arabica var. geisha & Altura & 3818.39 & $948.07^{\mathrm{i}}$ & $0.1118^{\mathrm{a}}$ & 3.36 \\
43 & C. arabica var. geisha & Altura & 4245.17 & $927.89^{\mathrm{j}}$ & $0.1285^{\mathrm{a}}$ & 3.85 \\
\hline
\end{tabular}

En la tabla 4, se observa que el contenido de cafeína de los cafés mezclados de Panamá varía de $0.05 \%$ a $0.52 \%$ y los cafés puros de Panamá, presentan un contenido de cafeína de $1 \%$ a $2 \%$ lo que confirma el rótulo de las marcas de café, que indica que es un café mezclado con maíz; esto explica el bajo contenido de cafeína de estos cafés ya que el maíz no aporta cafeína a la mezcla. La actividad antioxidante ABTS.+ de estos cafés está en el rango de 0.02 a $0.07 \mathrm{mmoles}$ trolox $/ \mathrm{g}$; este bajo valor de actividad antioxidante se debe a que el maíz de la mezcla no aporta compuestos que tengan actividad antioxidante como el café. La relación CQAs/Caf está en el rango de 0.05 a 1.53 que es una relación baja. Estos cafés mezclados no son considerados para hacer bebidas nutraceúticas porque su aporte en ácidos clorogénicos, como antioxidante, es bajo.

En la fig. 1 se muestra un cromatograma obtenido de una muestra de café variedad geisha a una longitud de onda de $325 \mathrm{~nm}$. Un total de 6 ácidos clorogénicos fueron identificados. Con el cromatograma obtenido por HPLC y las respectivas curvas de calibración se determinó la concentración de compuestos bioactivos presentes en los 34 cafés comerciales de Panamá. En la fig. 2 se muestra el gráfico entre el contenido de ácidos clorogénicos de los cafés puros comerciales de Panamá y su actividad antioxidante por el método del radical $A B T S S^{+}$. Se encontró una correlación de $\mathrm{R}^{2}=0.69$. Este resultado indica que los ácidos clorogénicos, componentes del café tienen un aporte significativo en la actividad antioxidante de este grano. La actividad antioxidante de los compuestos fenólicos es en general atribuido a sus grupos hidroxilos, entre otros factores (Shahidi y Chandrasekara, 2010). En otro estudio Vega et al., (2017) encontraron una 
correlación de $\mathrm{R}^{2}=0.83$ entre los polifenoles totales y la actividad antioxidantes de cafés puros de Panamá. Los ácidos clorogénicos son los compuestos bioactivos más abundantes del café y a eso se debe que explique en $69 \%$ la actividad antioxidante del café.

Tabla 4: Contenido de ácidos cafeoilquínicos (CQAs), cafeína, ABTS ${ }^{+}$, relación CQAS/Caf de los cafés mezclados comerciales de Panamá.

\begin{tabular}{llccccc}
\hline$\#$ & Composición & $\begin{array}{c}\text { Condiciones de } \\
\text { cultivo del café }\end{array}$ & $\begin{array}{c}\text { CQAs } \\
(\mathrm{mg} / 100 \mathrm{~g})\end{array}$ & $\begin{array}{c}\text { Caf } \\
(\mathrm{mg} / 10 \mathrm{gg})\end{array}$ & $\begin{array}{c}\text { ABTS }{ }^{+} \\
\left(\begin{array}{c}\text { mmoles eq. } \\
\text { Trolox/g }\end{array}\right.\end{array}$ & $\begin{array}{c}\text { Relación } \\
\text { CQAs /Caf }\end{array}$ \\
\hline 1 & Café y Maíz & Bajura & 76.86 & $307.31^{\mathrm{ef}}$ & $0.0271^{\text {def }}$ & 0.25 \\
2 & Café y Maíz & Bajura & 357.12 & $295.33^{\mathrm{f}}$ & $0.0296^{\mathrm{cde}}$ & 1.21 \\
3 & Café y Maíz & Bajura & 82.57 & $221.22^{\mathrm{g}}$ & $0.0247^{\mathrm{efg}}$ & 0.37 \\
4 & Café y Maíz & Bajura & 185.81 & $294.20^{\mathrm{f}}$ & $0.0313^{\mathrm{cde}}$ & 0.63 \\
6 & Café y Maíz & Bajura & 15.90 & $292.93^{\mathrm{f}}$ & $0.0212^{\mathrm{fg}}$ & 0.05 \\
10 & Café y Maíz & Bajura & 289.34 & $445.78^{\mathrm{b}}$ & $0.0379^{\mathrm{bc}}$ & 0.65 \\
13 & Café y Maíz & Bajura & 189.38 & $328.73^{\mathrm{d}}$ & $0.0350^{\mathrm{bcd}}$ & 0.58 \\
17 & Café y Maíz & Bajura & 38.82 & $52.28^{\mathrm{k}}$ & $0.0739^{\mathrm{a}}$ & 0.74 \\
20 & Café y Maíz & Bajura & 238.42 & $155.55^{\mathrm{i}}$ & 0.01649 & 1.53 \\
21 & Café y Maíz & Bajura & 55.92 & $173.63^{\mathrm{h}}$ & $0.0194^{\mathrm{fg}}$ & 0.32 \\
22 & Café y Maíz & Bajura & 306.58 & $320.19^{\mathrm{de}}$ & $0.0285^{\mathrm{cde}}$ & 0.96 \\
25 & Café y Maíz & Bajura & 226.69 & $414.58^{\mathrm{c}}$ & $0.0370^{\mathrm{bc}}$ & 0.55 \\
26 & Café y Maíz & Bajura & 563.89 & $521.39^{\mathrm{a}}$ & $0.0379^{\mathrm{b}}$ & 1.08 \\
27 & Café y Maíz & Bajura & 79.60 & $92.47^{\mathrm{j}}$ & $0.0168^{\mathrm{fg}}$ & 0.86 \\
28 & Café y Maíz & Bajura & 49.41 & $223.37^{\mathrm{g}}$ & $0.0204^{\mathrm{fg}}$ & 0.22 \\
29 & Café y Maíz & Bajura & 151.62 & $162.90^{\mathrm{hi}}$ & $0.0236^{\mathrm{efg}}$ & 0.93 \\
\hline
\end{tabular}

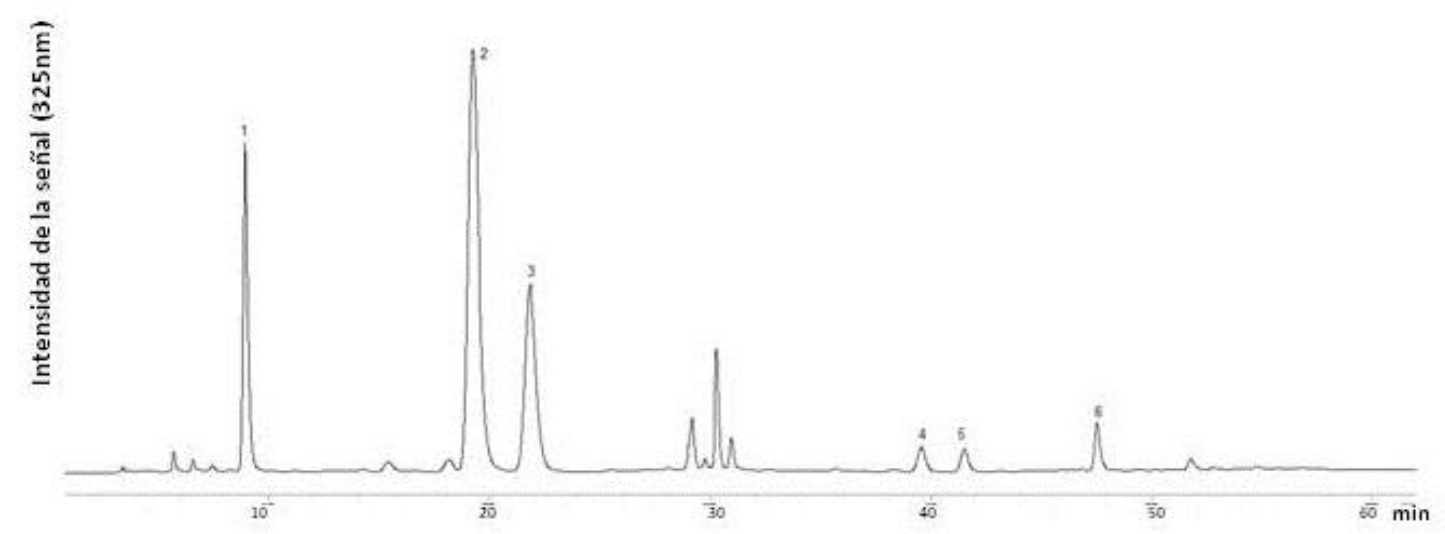

Fig. 1: Separación de ácidos clorogénicos en Café $C$. arabica tostado. 1= 3-CQA; 2= 5-CQA; 3= 4-CQA; 4= 3,4-diCQA; 5= 3,5-diCQA; $6=$ 4,5-diCQA.

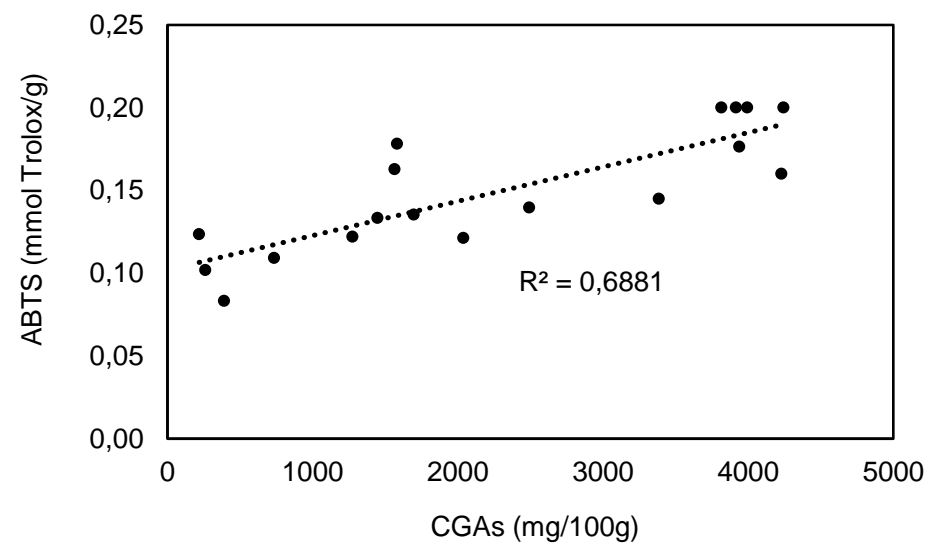

Fig. 2: Correlación entre el contenido de ácidos clorogénicos $(\mathrm{mg} / 100 \mathrm{~g})$ y actividad antioxidante por el método del radical ABTS ${ }^{+}\left(\mathrm{mmol}\right.$ Trolox/g), de las muestras de café puros. $R^{2}=0.69, \alpha=0.05$. 
En la fig. 3, se muestra el gráfico entre el contenido de cafeína de los cafés puros comerciales de Panamá y su actividad antioxidante por el método del radical ABTS.+. Se encontró una correlación de $\mathrm{R}^{2}=0.16$. Este resultado indica que la cafeína no tiene un aporte significativo en la actividad antioxidante de los extractos acuosos del café. En un estudio sobre los mecanismos de reacción de la cafeína con radicales libres LeónCarmona y Galano (2011), encontraron que la cafeína es un pobre reductor de radicales libres y que esta reacción depende de factores como la naturaleza de los radicales libres, la polaridad del medio.

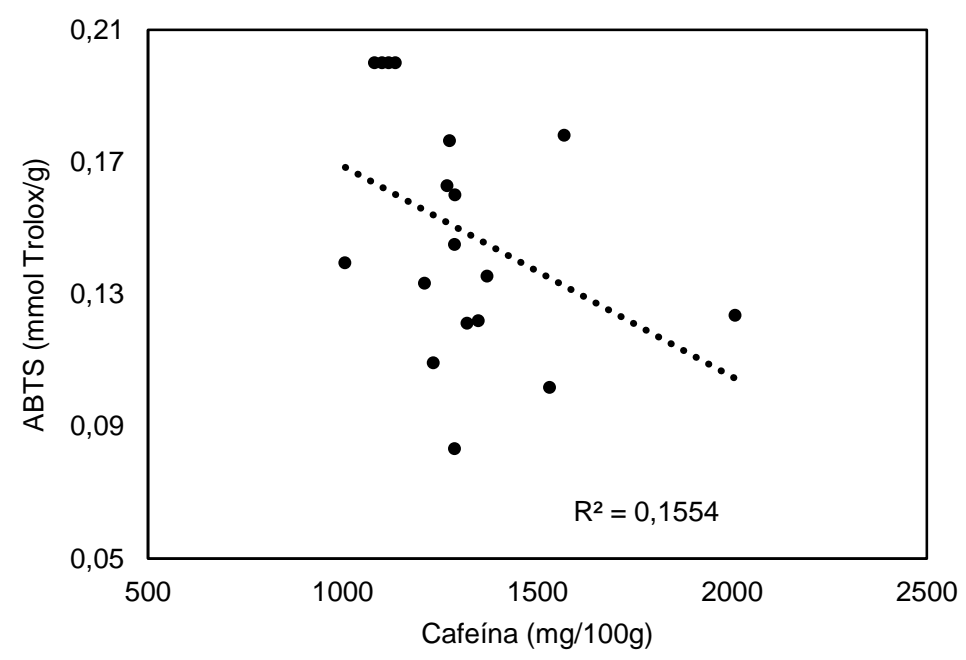

Fig. 3: Correlación entre el contenido de cafeína $(\mathrm{mg} / 100 \mathrm{~g})$ y actividad antioxidante método del radical $\operatorname{ABTS}^{+}\left(\mathrm{mmol}\right.$ Trolox/g), de las muestras de café puro comerciales de Panamá. $R^{2}=0.16, \alpha=0.05$.

En la fig. 4 se muestra el gráfico entre el contenido de los CQAs de los cafés mezclados comerciales de Panamá y su actividad antioxidante por el método del radical $A B T S S^{+}$. Se encontró un $\mathrm{R}^{2}=0.02 \alpha=0.05$. Este resultado nos indica que no existe correlación entre la actividad antioxidante y contenido de CQAs de los cafés mezclados. En muchas marcas del café mezclado, el maíz es el componente que está en mayor proporción y el mismo tiene un bajo contenido de ácidos clorogénicos, que son los componentes del café que mayor aporte hacen a la actividad antioxidante.

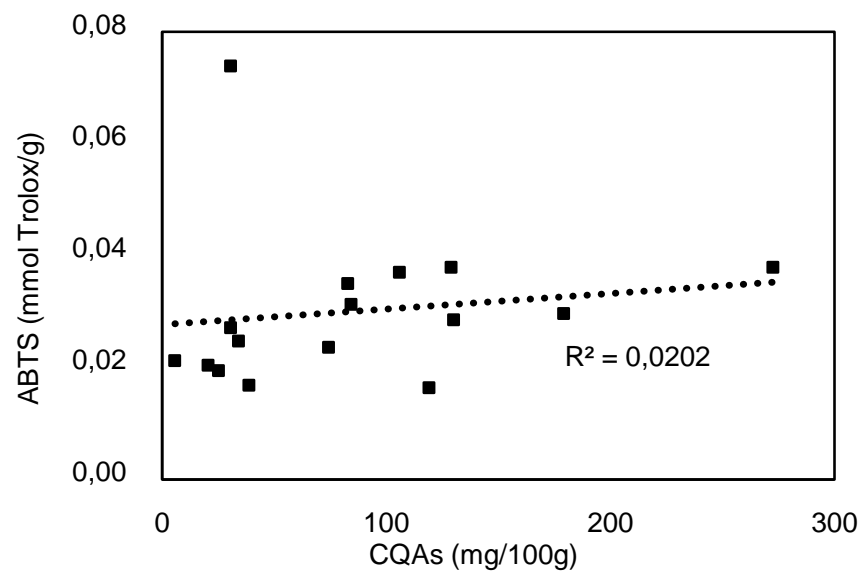

Fig. 4: Correlación entre el contenido de CQAs $(\mathrm{mg} / 100 \mathrm{~g})$ y actividad antioxidante por el método del radical $\mathrm{ABTS}^{+}\left(\mathrm{mmol}\right.$ Trolox/g), de las muestras de café mezclados. $\mathrm{R}^{2}=0.02, \alpha=0.05$.

En la fig. 5 se muestra que los cafés puros $C$. arabica var. geisha son los que tienen mayor contenido de 5CQA (1320.6 a $2042.32 \mathrm{mg} / 100 \mathrm{~g})$, y C. arabica var. pacamara $(1890.91 \mathrm{mg} / 100 \mathrm{~g}$ ) y las otras muestras de la especie C. arabica (86.31 a $936.78 \mathrm{mg} / 100 \mathrm{~g})$. Ya en estudios anteriores se encontró que el café geisha tenía el más alto contenido de polifenoles totales (3558 a $4595 \mathrm{mg} / 100 \mathrm{~g}$ ) (Vega et al., 2017); y los ácidos clorogénicos son los componentes mayoritarios de los polifenoles del café. El tostado como se ha demostrado (Jeon et al., 2017) disminuye el contenido de ácidos clorogénicos y según Marín (2008), esta reducción es de más del 90\%; en el caso de los cafés geisha en Panamá se le considera café especial, por lo que el tostado es cuidadoso y apenas pasa por el color chocolate claro que se logra a temperaturas de $208^{\circ} \mathrm{C}$ y tiempo de exposición 20 minutos. En esas condiciones de tostado los CGAs se descomponen menos y las concentraciones se mantienen altas como en el café verde (Samo et al., 2013). 


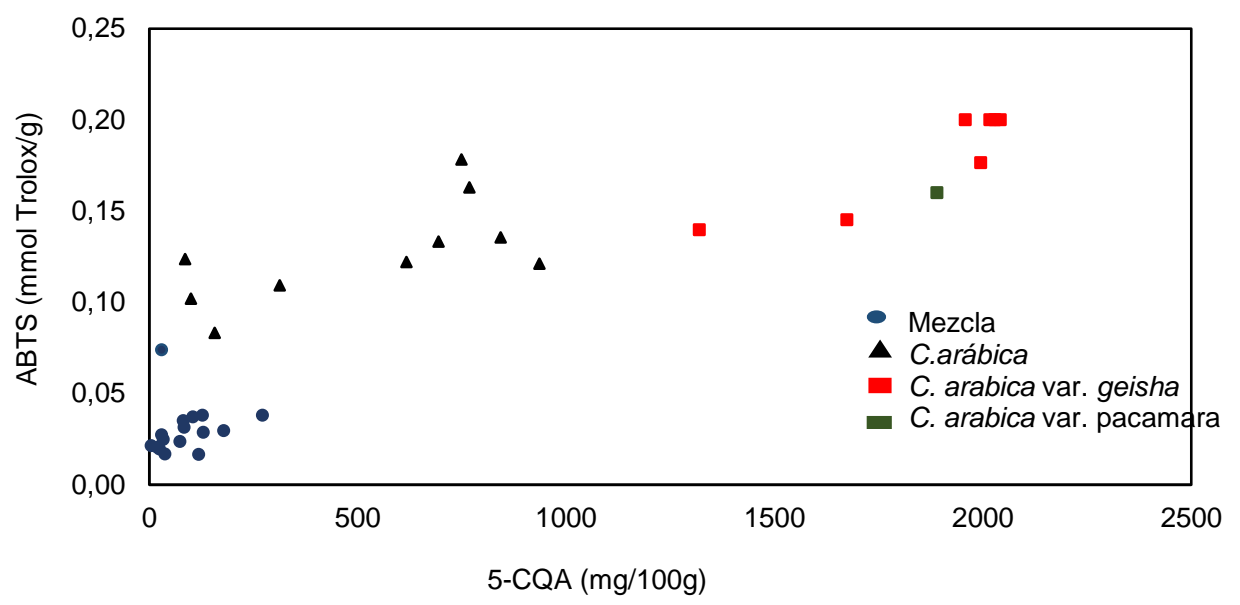

Fig. 5: Gráfico de dispersión del contenido de 5-CQA vs actividad antioxidante por el método del radical ABTS ${ }^{+}(\mathrm{mmol}$ Trolox/g), según la composición del café.

En los cafés la relación ácido clorogénico/cafeína da un indicio del grado de tostado ya que la cafeína no se descompone a las temperaturas de tostado y los ácidos clorogénicos si son lábiles a esas temperaturas (Ludwig et al., 2014; Jeon et al., 2017). Actualmente se busca un café que sea saludable por lo que debe tener un contenido bajo de cafeína y un contenido alto de ácidos clorogénicos, ya que el café es nuestra primera fuente de ácidos clorogénicos (Svilaas et al., 2004). Un consumo mayor de 400mg por día tiene efectos negativos en el sistema nerviosos central (Nawrot, 2003).

En la fig. 6 se muestra la concentración de los CGAs y cafeína de los 18 cafés puros estudiados. Se puede observar que $C$. arabica var. geisha de altura es la que contiene mayor cantidad de CGAs comparado a su contenido de cafeína y los de mayor contenido de cafeína en comparación con el contenido de CGAs son los $C$. arabica de bajura. En la fig. 7 se muestra la concentración de los CQAs y la cafeína de los cafés mezclados estudiados. En la mayoría de las muestras hay una concentración similar de CQAs que la concentración de la cafeína o menor.

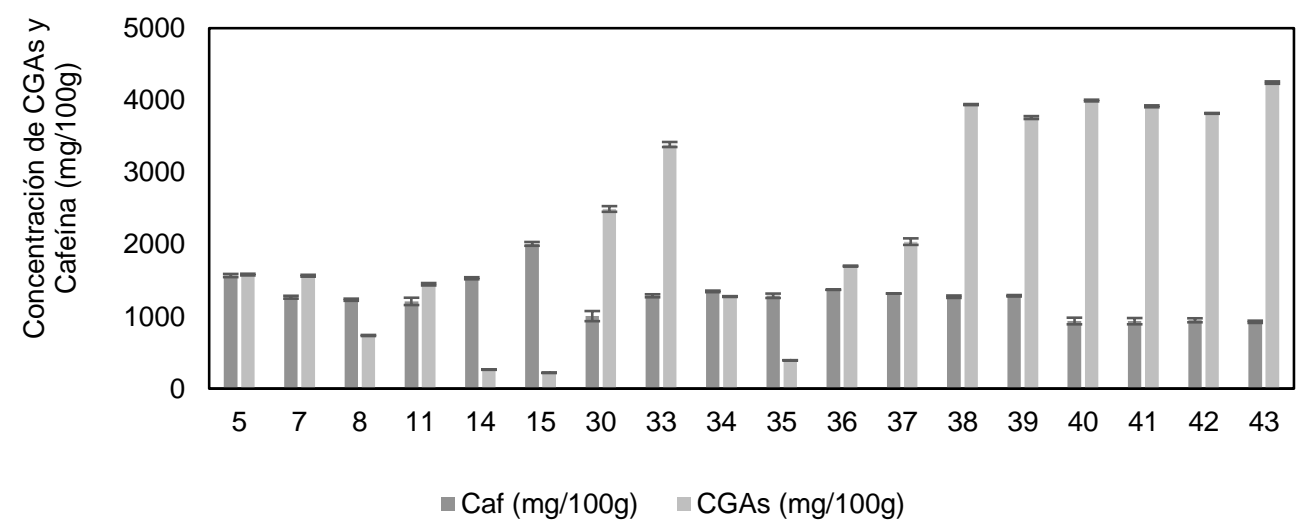

Fig. 6: Gráfico del contenido de Caf y CGAs, en mg/100g, de 18 marcas de café puros de Panamá.

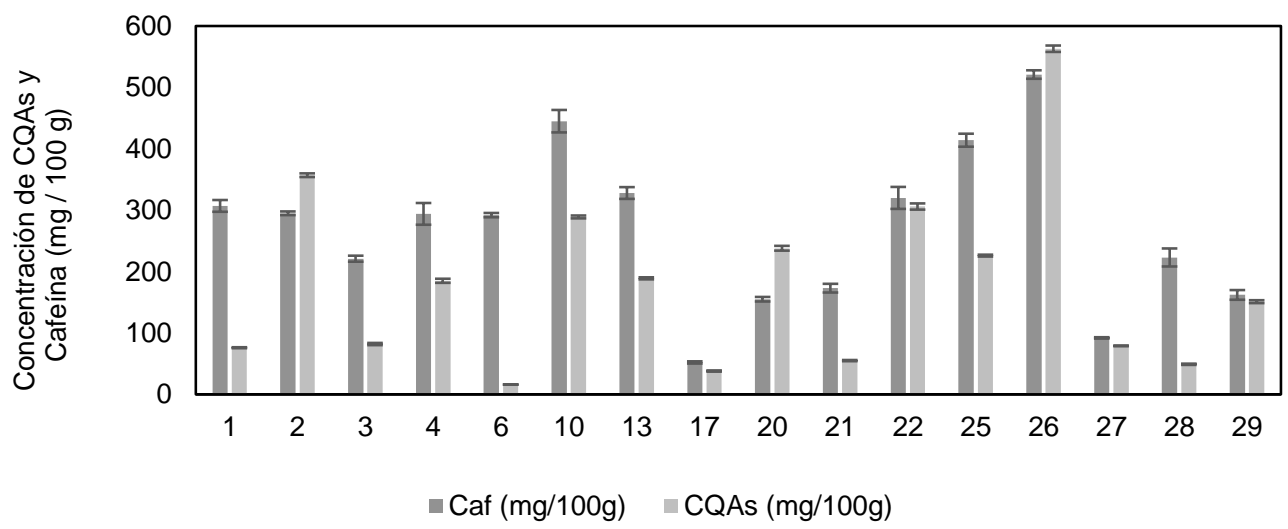

Fig. 7: Gráfico del contenido de Caf y CQAs, en mg/100g, de 16 marcas comerciales de cafés mezclados, de Panamá. 
En los cafés puros de Panamá las relaciones CGAs/Caf están en el rango de 0.11 a 3.85. Si se prepara una taza de café de $100 \mathrm{~mL}$ con $10 \mathrm{~g}$ de café se está consumiendo $92.79 \mathrm{mg}$ de cafeína y $394.22 \mathrm{mg}$ de ácidos clorogénicos. Esa persona puede tomar hasta 4 tazas de café y no supera los $400 \mathrm{mg}$ de cafeína, cantidad de consumo de cafeína limite no asociado con efectos adversos a la salud. Si se prepara una taza de café de $100 \mathrm{~mL}$ con agua caliente usando $10 \mathrm{~g}$ de la marca de café que tiene una relación CQAs/Caf de 0.11 se está consumiendo $200.09 \mathrm{mg}$ de cafeína y $21.9 \mathrm{mg}$ de ácido clorogénico. Con sólo una taza de café ese consumidor estaría ingiriendo 5 veces más cafeína, que lo recomendado para que no afecte su salud, y un bajo consumo de ácido clorogénico.

\title{
CONCLUSIONES
}

En el presente estudio se identificaron 10 compuestos bioactivos en las diferentes marcas de cafés comerciales de Panamá; seis ácidos clorogénicos (5-CQA, 4-CQA, 3-CQA, 3,4-diCQA, 3,5-diCQA y 4,5diCQA), cafeína, ácido gálico, ácido cafeico y ácido p-cumárico. De éstos, el ácido 5-CQA fue el compuesto que se encontró en mayor concentración. Del grupo de muestras analizadas, los cafés C. arabica var. geisha presentaron la mayor concentración de cada compuesto bioactivo. Por otra parte, la correlación obtenida entre los ácidos clorogénicos y la actividad antioxidante de las diferentes marcas de café, muestran que estos compuestos aportan un porcentaje importante a la capacidad antioxidante del café. En cambio, la correlación encontrada entre la cafeína y la actividad antioxidante, nos permite inferir que este componente no tiene un aporte significativo a la actividad antioxidante del café. Los cafés $C$. arabica var. geisha proporcionan el mayor contenido de ácidos clorogénicos por taza de café y presentaron una relación CGAs/Caf en el rango de 2.48 a 3.85, por lo que se puede proponer como fuente de antioxidantes de uso en varias industrias como la alimentaria, farmacéutica, nutracéutica y otros productos industriales.

\section{NOTACIÓN}

\author{
Abreviaciones \\ 5-CQA = ácido 5-cafeoilquínico \\ 4-CQA = ácido 4-cafeoilquínico \\ 3-CQA = ácido 3-cafeoilquínico \\ 3,4-diCQA = ácido 3,4-dicafeoilquínico \\ 3,5-diCQA = ácido 3,5-dicafeoilquínico \\ 4,5-diCQA = ácido 4,5-dicafeoilquínico \\ Caf = cafeína \\ CoA = ácido $p$-cumárico \\ $A G$ = ácido gálico \\ $\mathrm{CA}=$ ácido cafeico \\ $\mathrm{ND}=$ no detectado \\ ABTS $^{+}$= ácido 2,2' -azino-bis(3-etilbenzotiazolin-6-sulfónico) \\ CGAs = ácidos clorogénicos considerando los CQA y los diCQA \\ CQAs = ácidos cafeoilquínicos considerando solo los CQA \\ CGAs/Caf = relación ácidos clorogénicos/cafeína \\ CQAs/Caf = relación ácidos cafeoilquínicos/cafeína
}

\section{AGRADECIMIENTOS}

Los autores agradecen el apoyo brindado por la Vicerrectoría de Investigación y Posgrado de la Universidad Autónoma de Chiriquí VIP-UNACHI y al Sistema Nacional de Investigación de la Secretaría Nacional de Ciencia Tecnología e Innovación de Panamá SNI-SENACYT.

\section{REFERENCIAS}

Babova, O., A. Occhipinti y M.E. Maffei, Chemical partitioning and antioxidant capacity of green coffee (Coffea arabica and Coffea canephora) of different geographical origin, Phytochemistry, 123, 33-39 (2016)

Baeza, G., M. Amigo-Benavent, B. Sarriá, L. Goya, R. Mateos y L. Bravo, Green coffee hydroxycinnamic acids but not caffeine protect human HepG2 cells against oxidative stress, doi:10.1016/j.foodres.2014.05.035, Food Res. Int. (2014)

Clifford, M. y M.N. Clifford, Chlorogenic acids and other cinnamates - nature, occurrence, dietary burden, doi:10.1002/(SICI)1097-0010(20000515)80, J. Sci. Food Agric., 79, 362-372 (1999)

Farah, A. y C. M. Donangelo, Phenolic compounds in coffee, Braz. J. Plant Physiol., 18(1), 23-36 (2006)

Farah, A., T. DE Paulis, L.C. Trugo y P.R. Martin, Effect of Roasting on the Formation of Chlorogenic Acid Lactones in Coffee, J. Agric. Fod Chem., 53, 1505-1513 (2005) 
Grosso, G., U. Stepaniak, R. Topor-Madry, K. Szafraniec y A. Pajak, Estimated dietary intake and major food sources of polyphenols in the Polish arm of the HAPIEE study, Nutrition, 30, 1398-1403 (2014)

Guyot, B., D. Gueule, J.C. Manez, J.J. Perriot, J. Giron y L. Villain, Influence de l'altitude et de l'ombrage sur la qualité des cafés Arabica, Plant. Rech. Dévelop., 3, 272-283 (1996)

Hečimović, I., A. Belščak-Cvitanović, D. Horžić y D. Komes, Comparative study of polyphenols and caffeine in different coffee varieties affected by the degree of roasting, Food Chem., 129, 991-1000 (2011)

IUPAC, Commission on the Nomenclature of Organic Chemistry (CNOC) and IUPAC-IUB Commission on Biochemical Nomenclature (CBN), Nomenclature of Cyclitols, Biochem. J., 153, 23-31 (1976)

Jeon, J.S., H.T. Kim, H.H. Jeong, S.R. Hong, M.S. Oh, K.H. Park, J.H. Shim y A.M.A. EL-Aty, Determination of chlorogenic acids and caffeine in homemade brewed coffee prepared under various conditions, J. Chromatogr. B., 1064, 115-123 (2017)

Jeszka-Skowron, M., A. Sentkowska y K. Pyrzynska, Chlorogenic acids, caffeine content and antioxidant properties of green coffee extracts: influence of green coffee bean preparation, doi:10.1007/s00217-016-2643-y, Eur. Food Res. Technol., 242, 1403-1409 (2016)

Kreicbergs, V. y F. Dimins, Biologically active compounds in roasted coffee, FOODBALT, 110-115 (2011)

León-Carmona, J.R. y A. Galano, Is Caffeine a Good Scavenger of Oxygenated Free Radicals? J. Phys. Chem. B115, 4538-4546 (2011)

Luceri, C., L. Giannini, M. Lodovici, E. Antonucci, R. Abbate, E. Masisi y P. Dolara, p-Coumaric acid , a common dietary phenol, inhibits platelet activity in vitro and in vivo, doi:10.1017/S0007114507657882, British Journal of Nutrition 97, 458-463 (2017)

Ludwig, I., P. Mena, L. Calani, C. Cid, D. Del Río, M.E.J. Lean y A. Crozier, Variations in caffeine and chlorogenic acid contents of coffees: what are we drinking?, Food Funct., 5, 1718-1726 (2014)

Marín, G., Q. Puerta, Contenido de ácidos clorogénicos en granos de Coffea arabica L. y C. canephora, según el desarrollo del fruto, Cenicafé, 59(1), 7-28 (2008)

Miranda, A., Plan estratégico para el café 2007-2016. Ministerio de Desarrollo Agropecuario de Panamá, pp. 81 (2007)

Naegele, E., Determination of Chlorogenic Acid in Coffee Products According to DIN 10767, Application note Agilent, 49 (2016)

Nawrot, P., S. Jordan, J. Eastwood, J. Rotstein, A. Hugenholtz y M. Feeley, Effects of caffeine on human health, Food Additives \& Contaminants, 20(1), 1-30 (2003)

Nollet, L. y F. Toldrá, Handbook of Analysis of Active Compounds in Functional Foods, 491-492, Taylor \& Francis Group, Boca Raton, Florida, USA (2012)

Pantoja, A.L., A.M. Hurtado y H.A. Martínez, Evaluación del Rendimiento, Composición y Actividad Antioxidante de Aceite de Semillas de Mora (Rubus glaucus) Extraído con $\mathrm{CO}_{2}$ Supercrítico, Información Tecnológica, 28(1), 35-46 (2017)

Pérez-Hernández, L.M., K. Chávez-Quiroz, L.A. Medina-Juárez y N. Gámez Meza, Antioxidante de Café Verde y Procesado de las Especies Coffea arabica y Coffea Canephora, Biotecnia, 15, 51-56 (2012)

Perrone, D., A. Farah y C.M. Donangelo, Influence of coffee roasting on the incorporation of phenolic compounds into melanoidins and their relationship with antioxidant activity of the brew. J. Agric. Food Chem., 60, 4265-4275 (2012)

Shahidi, F. y A. Chandrasekara, Hydroxycinnamates and their in vitro and in vivo antioxidant activities, doi:10.1007/s11101-009-9142-8, Phytochem Rev., 9, 147-170 (2010)

Samo, S., S.E.W. Opitz, I. Vovk y Ch. Yeretzian, How does roasting affect the antioxidants of a coffee brew? Exploring the antioxidants capacity of coffee via on-line antioxidant assays coupled with size exclusion chromatography, Food Funct., 4 1082-1092 (2013)

Svilaas, A., A. Kaur Sakhi y otros seis autores, Intakes of Antioxidants in Coffee, Wine, and Vegetables are Correlated with Plasma Carotenoids in Humans, J. Nutr., 134, 562-567 (2004)

Vega, A., S. Reyes, J. De León, A. Bonilla y H. Franco, Cuantificación de cafeína en cafés comerciales de Panamá, Ciencia y Tecnología, 30(2), 57-64 (2014)

Vega, A., J.A. De León y S.M. Reyes, Determinación del Contenido de Polifenoles Totales, Flavonoides y Actividad Antioxidante de 34 Cafés Comerciales de Panamá, Información Tecnológica, 28(4), 29-38 (2017)

Wen, D., Y. Liu, Y. Liao y H. Liu, A Universal HPLC Method For The Determination Of Phenolic Acids In Compound Herbal Medicines, J. Agric. Food Chem., 53(17), 6624-6629 (2005)

Zanin, R.C., M.P. Corsoy otros tres autores, Good cup quality roasted coffees show wide variation in chlorogenic acids content, doi:10.1016/j.Iwt.2016.08.012, LWT - Food Sci. Technol. (2016) 